\title{
Por que alguém se fecha num quarto para escrever? a literatura como questão essencial no trabalho crítico de Maurice Blanchot
}

\author{
Why would someone lock himself in a room to write? \\ the literature as essential question in the critical work of Maurice Blanchot
}

\author{
Eduardo PELLEJERO ${ }^{1}$ \\ (Universidade Federal do Rio Grande do Norte)
}

Resumo: A literatura começa no momento em que se confronta com a sua própria opacidade e procura explorála através de uma pergunta essencial sobre si mesma (contra si mesma); começa no momento em que - numa inquisição sem reservas - transforma-se num processo sobre as suas razões e os seus poderes, as suas motivações e os seus fins. Por que, num mundo que ainda se debate numa luta sem tréguas pela liberdade, fechar-se num quarto para escrever?

Entre 1949 e 1959, Maurice Blanchot escrevia uma série de textos consagrados a pensar essa questão num registo ao mesmo tempo vindicativo e crítico, isto é, num registo que ao mesmo tempo justificava a soberania da literatura e problematizava o sentido da sua autonomia. O presente trabalho pretende interrogar o sentido dessa aproximação à literatura, explorando o seu alcance, avaliando os seus impasses e questionando os seus limites.

Palavras chave: Blanchot, literatura, autonomia, engajamento.

Resumen: La literatura comienza en el momento en que se confronta con su propia opacidad y busca explorarla a través de una pregunta esencial sobre sí misma (contra sí misma); comienza en el momento en que - en una inquisición sin reservas - se transforma en un proceso sobre sus razones y sus poderes, sus motivaciones y sus fines. ¿Por qué, en un mundo que todavía se debate en una lucha sin treguas por la libertad, encerrarse en un cuarto para escribir?

Entre 1949 y 1959, Maurice Blanchot escribía una serie de textos consagrados a pensar esa cuestión en un registro al mismo tiempo vindicativo y crítico, esto es, en un registro que al mismo tiempo justificaba la soberanía de la literatura y problematizaba el sentido de su autonomía. El presente trabajo pretende interrogar el sentido de esa aproximación a la literatura, explorando su alcance, evaluando sus impases y cuestionando sus límites.

Palabras clave: Blanchot, literatura, autonomía, compromiso

(...) uma breve consideração sobre o quarto. Por exemplo, a imagem de um homem sentado sozinho num quarto. Como em Pascal: "A infelicidade do homem sustenta-se só numa coisa: que é incapaz de ficar quieto no seu quarto". Como na frase: "escreveu o Livro da memória no seu quarto".

Paul Auster, A invenção da solidão

Por que alguém se fecha num quarto para escrever? Por que alguém volta às costas ao mundo? Por que alguém recusa desse modo a vida ativa? Proust: catorze anos sem sair da cama ("escrevendo

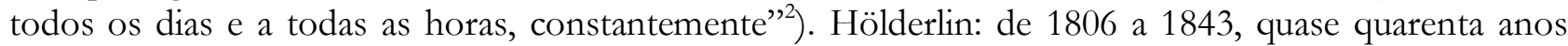
recluído na sua casa! Garcia Marques: seis meses sem deixar a caverna nem para almoçar com a família.

\footnotetext{
1 Argentino de nascimento, português por adoção, residente no Brasil, apátrida por convicção. Atualmente é professor de Estética Filosófica na Universidade Federal do Rio Grande do Norte, onde desenvolve uma investigação no domínio da filosofia (política) da arte. Publicou «Deleuze y la redefinición de la filosofía» (México: Jitanjáfora, 2006) e «A postulação da realidade» (Lisboa: Vendaval, 2009). E-mail: estética.ufrn@gmail.com

2 BLANCHOT, 2005, p. 306
} 
Xavier de Maistre: quarenta e dois dias confinado no seu quarto, condenado ao seu quarto (e escreve! ${ }^{3}$ ). Kafka: longas sessões noturnas de até quinze horas, só no seu escritório ("só como Franz. Kafka")."

Por que alguém se isolaria dessa forma? Por que alguém se condenaria a essa espécie de naufrágio voluntário? Joyce: usarei na minha defesa as únicas armas que me permito usar: astúcia, silêncio, exilio. ${ }^{5}$ Gombrowicz: o mundo é uma hipótese desnecessária. ${ }^{6}$ Pizarnik: a tinta é o meu único consolo (e tem apenas 19 anos!).

Poderíamos alegar (muitos já o fizeram) uma falha no caráter, uma fraqueza na substância moral, uma doença - e, certamente, muitos grandes escritores foram também grandes doentes, grandes falhados. Mas nenhuma doença, nenhuma falha é suficiente para iluminar, nem que seja só com uma luz obscura, o que se encontra em jogo nesse gesto ao mesmo tempo de um desespero total e de um otimismo sem limites ${ }^{7}$ alguém se fecha num quarto para escrever.

A literatura começa no momento em que se confronta com essa questão, que denuncia a sua própria opacidade, e procura explorá-la através de uma pergunta essencial sobre si mesma (contra si mesma); nesse momento em que - numa inquisição sem reservas - transforma-se num processo sobre as suas razões e os seus poderes, as suas motivações e os seus fins. Por que, num mundo que ainda se debate numa luta sem tréguas pela liberdade, fechar-se num quarto para escrever? Para que servem os poetas em tempos de aflição (sendo que para os poetas os tempos são sempre de aflição)?

Entre 1949 e 1959, Maurice Blanchot escrevia uma série de textos consagrados a pensar essa questão num registo ao mesmo tempo vindicativo e crítico, isto é, num registo que ao mesmo tempo justificava a soberania da literatura e problematizava o sentido da sua autonomia.

$\mathrm{Na}$ convicção de que a renúncia do escritor a interessar-se por qualquer coisa e voltar-se para a parede não iliba a literatura de uma série de laços paradoxais com o mundo (BLANCHOT, 2011a, p. 320), Blanchot empreende uma investigação sobre o espaço literário - o "espaço fechado, separado e sagrado que é o espaço literário" (BLANCHOT, 2005, p. 303) - e as suas relações com a práxis humana. Porque escrever é entrar num templo, mas é também, simultaneamente, querer destruir o templo ${ }^{8}$.

O caminho trilhado por Blanchot, em todo o caso, encontra-se balizado pelo diagnóstico hegeliano da caducidade da arte, segundo o qual, desde que o absoluto se reconhece na racionalidade

\footnotetext{
3 “O prazer que se sente ao viajar em seu quarto está a salvo da inveja inquieta dos homens, e independe da fortuna. Haverá alguém, realmente, tão infeliz, tão abandonado, que não tenha um reduto aonde possa se retirar e se esconder de todo mundo?" (Xavier de Maistre, Viagem em volta do meu quarto, tradução portuguesa de Sandra M. Stroparo, São Paulo: Hedra, 2009, p. 25)

${ }^{4}$ Marguerite Duras: vinte anos numa casa, também : “A solidão não se encontra, faz-se. A solidão faz-se sozinha. Eu a fiz. Porque decidi que era aí onde devia estar só, onde estaria só para escrever livros. Aconteceu assim. Estava sozinha em casa. Encerrei-me nela, também tinha medo, claro. E depois a amei. A casa, esta casa, converteu-se na casa da escrita. Os meus livros saem dessa casa. Também dessa luz, do jardim. Dessa luz refletida no estanque. Necessitei vinte anos para escrever o que acabo de dizer." (Duras, 1994)

5 "You have asked me what I would do and what I would not do. I will tell you what I will do and what I will not do. I will not serve that in which I no longer believe, whether it call itself my home, my fatherland or my church: and I will try to express myself in some mode of life or art as freely as I can, and as wholly as I can, using for my defence the only arms I allow myself to use ... silence, exile, and cunning." (Joyce, A Portrait of the Artist As a Young Man, Nu Vision Publications, 2009, p. 187)

6 "Soy solo. Por eso soy más." (Grombowicz, Diario 1 (1953-1956), Madrid: Alianza, 1988; p. 357)

7 Desespero, porque dar as costas ao mundo é assumir a vaidade da ação histórica, da impostura da salvação pelas obras, numa época em que nos é vedada a via da graça. Optimismo, porque escrevendo desde as profundezas da sua solidão, o escritor fala (mesmo sem dizer nada) para um leitor que eventualmente acolherá a sua obra numa solidão não menos profunda (e a achará significativa); logo, fé cega na essencial igualdade dos homens, na possibilidade de uma comunicação sem mediações, sem objeto, sem fim. "Escrevendo, [o escritor] não pode sacrificar a noite pura das suas possibilidades próprias, porque a obra só vive se essa noite - e não outra - se faz dia, se o que há nele de mais singular e mais afastado da existência já revelada se revela na existência comum" (BLANCHOT, 2011a, p. 317). Optimismo desesperado, dir-se-ia.

8 “[S]e escrever é entrar num templum que nos impõe, independentemente da linguagem que é a nossa, por direito de nascimento e por fatalidade orgânica, um certo número de usos, uma religião implícita, um rumor que muda de antemão tudo o que podemos dizer, que o carrega de intenções tanto mais ativas quanto mais dissimuladas, escrever é primeiramente querer destruir o templo antes de o edificar; é pelo menos, antes de ultrapassar seu limiar, interrogar-se sobre as servidões daquele lugar, sobre o pecado original que constituirá a decisão de fechar-se nele. Escrever é, finalmente, recusar-se a ultrapassar o limiar, recusar-se a "escrever" (BLANCHOT, 2005, p. 303)
} 
moderna e no trabalho do negativo no mundo, a arte deixa de ser capaz de satisfazer-nos enquanto sujeitos da história, perdendo a sua realidade, a sua efetividade, a sua necessidade ${ }^{9}$. Num tempo no qual só conta a realização do mundo, a seriedade da ação e a tarefa da liberdade real, a arte parece encontrar apenas um lugar de sobrevivência nos museus, onde opera como agente de prazer estético ou mistificação cultural ${ }^{10}$.

Tal é o sentido da assimilação hegeliana da arte a coisa do passado: considerada desde o ponto de vista da sua participação na obra humana geral e na afirmação de um dia pleno - a construção desse mundo verdadeiro no qual a liberdade reside -, a arte "age mal e pouco" (BLANCHOT, 2011b, p. 231). A maior obra não vale o ato mais insignificante (BLANCHOT, 2011a, p. 348). Mesmo não se reduzindo a um instante de sonbo, um puro sorriso interior, mesmo querendo-se atuante, mobilizadora, comovente, a arte é de uma total ineficácia - ineficácia que se encontra indissociavelmente ligada às leis do jogo que propõe.

A arte quer edificar, mas segundo ela própria e sem nada acolher do dia senão o que é adequado à sua tarefa. Ela tem certamente por objetivo algo de real, um objeto, mas um belo objeto: isso quer dizer que será objeto de contemplação, não de uso, e que, além disso, se bastará, repousará em si mesmo, não remeterá para nenhuma outra coisa, será o seu próprio fim (segundo as duas acepções da palavra). (BLANCHOT, 2011b, p. 230)11

Logo, confrontada com a razão moderna - e com o seu sentido último: a eficácia da razão histórica -, a arte não pode deixar de considerar-se alheia à razão. Isso não significa simplesmente privilegiar a economia política sobre a ficção literária; significa que para a nossa consciência histórica, nos tempos conturbados que vivemos, "a obra de arte está fora de questão" (Gide apud BLANCHOT, 2011b, p. 233). Numerosos escritores - Char, Gide, Hölderlin, etc. - referendaram essa difícil posição, aprofundando a questão que para nós levanta a literatura: "A atividade artística, mesmo para aquele que a escolheu, revela-se insuficiente nas horas decisivas, essas horas que soam a cada hora, em que 'o poeta deve completar sua mensagem pela recusa de si”" (BLANCHOT, 2011b, p. 232) ${ }^{12}$. Enquanto atividade, a arte é uma forma menor, uma espécie de atividade mediata, reservada - votada, portanto, a apagar-se diante da ação imediata e sem reserva da tarefa histórica. Há uma incompatibilidade entre o engajamento e a literatura (Bataille), e a verdade é que na modernidade cumpre ser Brutus, não pintar o assassinato de César (BLANCHOT, 2011b, p. 233).

\footnotetext{
9 “'Hegel, ao iniciar seu curso monumental sobre a estética, pronunciava estas palavras: 'A arte é, para nós, coisa passada' (...) O que quereria ele dizer, ele, que não falava levianamente’? Apenas isto, precisamente: que a partir do dia em que o absoluto se tornou, conscientemente, trabalho da história, a arte deixou de ser capaz de satisfazer a necessidade de absoluto: tudo o que ele tinha de autenticamente verdadeiro e vivo pertence agora ao mundo e ao trabalho real no mundo." (BLANCHOT, 2011b, p. 233).“O perigo é que a arte seja meramente estimada e perca a sua necessidade e a sua vocação pelo absoluto. Blanchot aspira a restaurar um estatuto exaltado para a arte. Nesse sentido, ele aceita demasiado facilmente o ponto de partida de Hegel: a arte e a literatura devem ser absolutas de direito. E uma vez identificado o estatuto desvalorizado da arte com a sua falta de mundo, a sua historicidade e a sua contingência, a única via para que a literatura volte a ser nobre novamente é devir de outro mundo. Isso significa que deve devir metafisica - isto é, 'mais original' - ou impossível. Blanchot oscila entre definições nas quais a arte é, ora uma coisa, ora outra. O 'espaço literário' é portanto além da razão (é o domínio da contradição e da angustia), além da verdade (é o domínio do erro) e além dos seres (é o nada)." (SCHWARTZ, 1998). "[T]o be more precise, the philosophy of Hegel as it is presented by the Russian émigré philosopher Alexander Kojève (1902-68), whose lectures on Hegel not only decisively influenced Blanchot's ideas on literature, but a whole generation of French intellectuals. We shall also see that for Blanchot this Hegelian conception of language is strongly mediated by the remarks on language and poetry by the French Symbolist poet Stéphane Mallarmé (1842-98).” (HAASE \& LARGE, 2001, p. 25)

10 Sobrevivência patética, que manifesta a decadência da sua significação nas nossas sociedades.

11 “A obra (...) contém o princípio da sua ruína. E o que a arruína é que ela parece verdadeira, é que desse semblante de verdade aduz-se uma verdade ativa e um falso semblante inativo a que se chama o belo, dissociação a partir da qual a obra torna-se uma realidade mais ou menos eficaz e um objeto estético." (BLANCHOT, 2011b, p. 251)

12 "Para onde quer que volte o meu olhar, nada vejo ao meu redor senão sofrimento e aflição. Aquele que permanece contemplativo, hoje, dá prova de uma filosofia inumana ou de uma cegueira monstruosa." (GIDE apud BLANCHOT, 2011b, p. 233n)
} 
É certo que em "A literatura e o direito à morte" Blanchot assimilava o labor do escritor àquilo que faz o homem que trabalha. De certa forma, com efeito, através do livro o escritor exerce um poder de negação e transformação, nega o mundo dado e afirma um mundo porvir, dando lugar a uma série de coisas (não apenas novos livros) pelos projetos que inspira, as empresas que propicia, as possibilidades que insinua. Noutras palavras, a literatura pode manifestar-se também como fermento da história, revelando ao homem a totalidade da qual forma parte - negando o que é, afirmando o que não é -, contribuindo assim para o devir da consciência (BLANCHOT, 2011a, p. 324 e 347).

Mas ao mesmo tempo, na especificidade do labor literário, Blanchot identificava o princípio da sua inoperância, que torna o ato de escrever uma pura passividade à margem da história (e que a história arrasta consigo apesar de tudo). Ao contrário do trabalho efetivo, o labor literário tem lugar no vazio (não é um trabalho verdadeiro): negando tudo o que é (na realidade) para ser o que não é (na ficção), o escritor dá-se uma liberdade que não possui, descuidando as verdadeiras condições da sua emancipação (e dos seus leitores).

[O escritor] negligencia o que deve ser feito de real para que a ideia abstrata de liberdade se realize. Sua negação particular é global. Ela não nega apenas sua situação de homem entre muros, mas também passa por cima do tempo que deve abrir brechas nesses muros, nega a negação do tempo, nega a negação dos limites. Por essa razão, em suma, não nega nada, e a obra em que se realiza não é ela própria um ato realmente negativo, destruidor e transformador, mas realiza a impotência de negar, a recusa de intervir no mundo, e transforma a liberdade que seria preciso encarnar nas coisas segundo os caminhos do tempo num ideal acima do tempo, vazio e inacessível. (BLANCHOT, 2011a, p. 325 - modificado) ${ }^{13}$

Blanchot assinala que nessa ambiguidade própria da literatura radica um risco: não o risco do quietismo que pode seguir-se da passagem da realidade para o imaginário, mas o risco da inoperância de um gesto que coloca à nossa disposição toda a realidade, isto é, conduz à irrealidade (porque a irrealidade começa com o todo ${ }^{14}$ ). O grande dom da literatura - ver a simultaneidade do universo sem sair do nosso quarto ${ }^{15}$ - é ao mesmo tempo a sua falha. As coisas (as realidades particulares) são colocadas fora de jogo através desse gesto que define a ficção, assim como é colocado fora de jogo o trabalho necessariamente paciente da sua transformação no tempo, tudo isso à conta do gozo imediato de uma variação imaginária ${ }^{16}$. Passando sem mediações do nada ao todo, o apelo do escritor à liberdade dos seus leitores é um "apelo vazio, expressando somente o esforço de um homem privado de mundo para voltar ao mundo, mantendo-se discretamente na sua periferia" (BLANCHOT, 2011a, p. 326) ${ }^{17}$.

Alguém se fecha num quarto para escrever, substituindo o mundo dos trabalhos e dos dias (concreto, definido, determinado) por um mundo elusivo e precário (mas total, completo, pleno) que se oferece sem atrito ao prazer solitário da leitura (porque alguém também se fecha num quarto para ler). O escritor e o leitor conhecem esse privilégio de superar o lugar e o momento atuais para se situarem

${ }^{13}$ É notável, nisso, a proximidade com a abordagem que Sartre propõe da liberdade literária no segundo capítulo de $O$ que é a literatura?

14 “A irrealidade começa com o todo. O imaginário não é uma estranha região situada além do mundo; é o próprio mundo, mas o mundo como conjunto, como o todo.” (BLANCHOT, 2011a, p. 325)

${ }_{15} \mathrm{Na}$ sua obra, Enrique Vila-Matas retoma esta e muitas das referências do escritor fechado no seu quarto do livro de Auster, exceção feita - quiçá - de Xavier de Maistre. Essa divida é saldada parcialmente em Dublinesca, onde a atribuição a Auster é finalmente explicitada (devo essa referência à Nadier Pereira dos Santos e ao seu trabalho sobre a poética de VilaMatas).

16 "Compreendemos a desconfiança dos homens engajados num partido, tendo tomado partido, em relação aos escritores que compartilham suas opiniões; pois esses também tomaram o partido da literatura, e a literatura, por seu movimento, nega, no final de contas, a substância do que representa. Essa é sua lei e sua verdade. Se renunciar a isso para se ligar definitivamente a uma verdade exterior, cessa de ser literatura, e o escritor que ainda pretende sê-lo entra em outro aspecto da má-fé." (BLANCHOT, 2011a, p. 320)

17 "Muito mais mistificadora é a literatura de ação. Esta incita os homens a fazer alguma coisa. Mas, se quiser ser ainda literatura autêntica, ela lhes representa esse algo a fazer, essa meta determinada e concreta, a partir de um mundo onde uma ação dessas remete à irrealidade de um valor abstrato e absoluto. $O$ 'algo a fazer', tal como pode ser expresso numa obra da literatura, é apenas um 'tudo a fazer', seja porque se afirma como esse tudo, isto é, valor absoluto, seja porque para se justificar e se recomendar precise desse tudo no qual desaparece.” (BLANCHOT, 2011a, p. 326) 
nas margens do mundo e nos confins do tempo (no alto da noite, no silêncio de um quarto), para daí falar (ouvir) das coisas e dos homens ${ }^{18}$. Instancias de uma liberdade absoluta, mas sem efetividade alguma, cuja soberania não conhece correlato histórico (fora desses momentos extraordinários nos quais tudo parece possível, a palavra da fábula devém ação e a literatura se faz história sob a forma do acontecimento revolucionário ${ }^{19}$ ). "Tibete imaginário", diz Blanchot (2005, p. 321).

Em certo sentido, é desnorteante que Blanchot conceda o jogo a Hegel dessa forma claudicante e excessiva, reduzindo o labor literário a um trabalho de nada. É verdade que a polêmica levantada pelas formulações coevas do engajamento literário comprometiam muitas vezes a escritura em caminhos de duvidosa destinação, cancelando a dúvida essencial da literatura sobre a sua própria potência à conta de uma fé cega em empresas extraliterárias. Mas também é verdade que nas formas mais interessantes dessa luta pelo direito da literatura a ocupar um lugar na história - em René Char, em Marguerite Duras, inclusive em Sartre - as respostas propostas não obliteravam a pergunta e não professavam outra fé que a suscitada pela própria literatura - em René Char, em Marguerite Duras, sobretudo em Sartre. Como entender, portanto, a recusa de Blanchot? Quero dizer: em que consiste a suposta "superabundância da recusa" (BLANCHOT, 2011b, p. 234)?

A resposta é que Blanchot, concedendo a sua marginação histórica, faz jogar a literatura noutro tabuleiro. A arte, inútil para o mundo, possui apesar de tudo um valor que não se avalia. Nas margens ou nos interstícios da história, a literatura faz da sua reserva, da sua soberania interior, testemunho de um resto inútil, insignificante, menor, que é capaz de desfundar todo o edifício hegeliano (impugnando as suas teses por defeito $)^{20}$.

Se Kafka, Hölderlin, Mallarmé, Rilke, Breton, Char, continuam a fazer da literatura um absoluto, a consagrar-lhe as suas noites e sacrificar-lhe os seus dias, se os escritores continuam a fecharse num quarto para escrever, de cara contra a parede, de costas para o mundo, é em virtude desse excesso (desse defeito) que constitui um modo essencial de autenticidade não ligado à forma do verdadeiro (BLACHOT, 2011b, p. 261).

Isto quer dizer que pela literatura, através da questão que a literatura coloca sobre a sua própria essência, sobre a sua possibilidade e o seu sentido, é a totalidade dos projetos humanos que é colocada em questão. A ausência de fundamento que a literatura abraça ${ }^{21}$, na sua recusa da verdade e no seu exercício da ficção, projeta uma sombra crítica sobre a práxis histórica. Dir-se-ia que coloca o mundo entre parêntesis, suspendendo as suas redes significantes (o valor das suas categorias e dos seus conceitos), remetendo a vida para uma dimensão aquém do saber, expressando relações que precedem

\footnotetext{
18 “O que é uma obra? Palavras reais e uma história imaginária, um mundo onde tudo o que acontece é tirado da realidade, e esse mundo é inacessível; personagens que se querem vivos, mas sabemos que sua vida é feita de não viver (de permanecer ficção); então, um puro nada? Mas o livro está ali, nós o tocamos, as palavras são lidas, não podemos mudá-las; o nada de uma ideia, do que só existe compreendido? Mas a ficção não é compreendida, é vivida sobre as palavras a partir das quais se realiza, e é mais real, para mim que a leio ou a escrevo, do que muitos acontecimentos reais, pois se impregna de toda a realidade da linguagem e se substitui à minha vida à força de existir.” (BLANCHOT, 2011a, p. 248)

19 "Momentos fabulosos, com efeito: neles fala a fábula, neles a palavra da fábula se faz ação. Se tentam o escritor, nada mais justificado. A ação revolucionária é, em todos os pontos, análoga à ação tal como é encarnada pela literatura: passagem do nada ao tudo, afirmação do absoluto como acontecimento e de cada acontecimento como absoluto. A ação revolucionária se desencadeia com a mesma força e a mesma facilidade que o escritor que, para mudar o mundo, só precisa alinhar algumas palavras. Ela tem também a mesma exigência de pureza e essa certeza de que tudo o que faz vale completamente, não é uma ação qualquer com relação a alguma meta desejável e estimável, mas a meta única, o Último Ato. Esse último ato é a liberdade, e só existe escolha entre a liberdade e o nada. É por isso que, então, a única frase suportável é: liberdade ou morte. Assim aparece o Terror.” (BLANCHOT, 2011a, p. 328)

20 "Em aparência, essa crise e essa crítica lembram apenas, ao artista, a incerteza de sua condição na civilização poderosa em que ele tem pouca participação. Crise e crítica parecem vir do mundo, da realidade política e social, parecem submeter a literatura a um julgamento que a humilha em nome da história: é a história que critica a literatura, e que empurra o poeta para um canto, colocando em seu lugar o publicitário, cuja tarefa está a serviço dos dias. Isso é verdade, mas, por uma coincidência notável, essa crítica estrangeira corresponde à experiência própria que a literatura e a arte conduzem por elas mesmas, e que as expõe a uma contestação radical.” (BLANCHOT, 2005, p. 289)

${ }^{21} \mathrm{O}$ fundo, a soçobra, pertencem à arte: esse fundo que ora é ausência de fundamento, o puro vazio sem importância, ora é aquilo a partir do qual pode ser dado um fundamento - mas que também é sempre ao mesmo tempo, um e outro (BLANCHOT, 2011b, p. 261)
} 
qualquer realização objetiva (BLANCHOT, 2005, p. 288): "Escrever (...) é retirar a palavra do curso do mundo, desinvesti-la do que faz dela um poder pelo qual, se eu falo, é o mundo que fala, é o dia que se edifica pelo trabalho" (BLANCHOT, 2011b, p. 17) ${ }^{22}$.

No seu singular jogo de significação, a literatura não designa o mundo, nem afirma um (novo) sentido do mundo, mesmo que um mundo, ou vários, possam insinuar-se nas suas palavras (e nesse sentido, a literatura não diz nada ${ }^{23}$. Sob a superfície das fábulas que conta, das estórias que canta, é a existência de um ser sem determinação que se faz ouvir (e, nesse sentido, é o nada que fala na literatura $)^{24}$.

A estranheza dessa fala é que ela parece dizer algo, enquanto talvez não diga nada. Ainda mais, parece que a profundidade nela fala, e o inédito nela se faz ouvir. (BLANCHOT, 2005, p. 321) ${ }^{25}$

O privilégio dado por Blanchot à palavra poética, a sua defesa do valor absoluto da arte depois do diagnóstico hegeliano, encontra-se associado a essa dupla condição da literatura: ser, por um lado, uma "morada de silêncio" (Blanchot, 2005, p. 320), isto é, suspensão das estruturas de sentido de um mundo histórico dado; furtar-se, por outro lado, a qualquer determinação essencial, estar sempre por definir, por reinventar, por $\operatorname{vir}^{26}$, isto é, remeter à origem.

Não se trata de uma metáfora, de um símbolo. Como para o romantismo, para Blanchot há uma relação essencial entre o absoluto e a literatura. A questão que a obra moderna levanta sobre a

${ }^{22}$ No centro da experiência literária se encontra em jogo uma forma da linguagem que nos separa da vida, abrindo uma distância entre nós (escritores ou leitores) e o mundo (HAASE \& LARGE, 2001, p. 22) Blanchot escreve: "é para cada um uma necessidade procurar desligar-se desse mundo, e é uma tentação, para todos, a de arruiná-lo, a fim de o reconstruir puro de todo uso anterior, ou ainda melhor, de deixar o lugar vazio." (BLANCHOT, 2005, p. 303) “A linguagem essencial contrariamente à linguagem bruta -, sob a forma e a potência da negação e da supressão, designa o Outro ('algo diferente') do saber e do mundo, o seu negativo linguístico tornado possível pela sua designação no espaço ficcional: é a especificidade da criação poética quando é fundada, imaginariamente, sobre a linguagem literária.” (MIRAUX, 1998, 1998, p. 13) “The essential character of language is its power of abstraction; that is to say, its distance from the reality of things. This distance Blanchot and Mallarmé interpret as the power of language to negate the actual, individual concrete thing, for the sake of the idea of a thing in language, writes Blanchot, 'speech has a function that is not only representative but also destructive. It causes to vanish, it renders the object absent, it annihilates it'. What happens in the information model of language is that it forgets this essence of language. It forgets that language, even before some meaning is expressed, is this distance from things. As speaking beings we are always already banished from the immediacy of things. We are suspended in the absence of language, and this suspension is what prevents language from finding stability in an extra-linguistic reality. The word 'tree' does not ever just mean this or that tree, for it has already withdrawn itself from their reality. Even the idea tree is a poetic fragment that has forgotten its moment of creation. According to Blanchot and Mallarmé, the absence of language is covered over or concealed by the idea or concept expressed in the word." (HAASE \& LARGE, 2001, p. 31) "[A experiência do fora própria da literatura] é a experiência do fora que se abre no interior da própria linguagem, um fora de todo o discurso significativo que, no entanto, não constitui um limite da linguagem, dado que se trata de uma abertura que a ilimita do interior." (SAN PAYO, 2008, p. 17)

23 'Tout d' abord, comme le fit Sartre pour le deuxième roman de Blanchot, l'on peut envisager une interprétation du récit en le répertoriant dans les récits fantastiques. En l'incluant dans une problématique de l'intrusion de l'inadmissble et de l'inquiétude dans la réalité quotidienne (ce sont les définitions proposées par Roger Caillois, Tzvetan Todorov, PierreGeorges Castex ou Louis Vax), Sartre, met en relation le texte blanchotien avec le monde du quotidien et interprète son univers en rapport avec le référentiel ou la réalité; ce faisant, il nie l'autonomie textuelle et offre une signification à un récit qui, précisément, voulait se situer dans le dehors de tout monde et non comme son envers ; alors que le récit fantastique fonctionne essentiellement dans la relation avec l'univers humain, le récit blanchotien fonctionne en relation avec ses propres lois qui sont celles de l'espace d'écriture.” (MIRAUX, 1998, p. 23)

24 "O ser das coisas não é nomeado na obra, mas diz-se na obra, coincide com a ausência das coisas que são as palavras." (LEVINAS apud SCHWARTZ, 1996). "[S]ó a literatura é capaz de colocar entre parênteses o mundo dos conceitos, das ideias e dos significados, em ordem a trazer à superfície aquilo sobre o que repousa esse mundo.” (SCHWARTZ, 1996) "Num texto sobre a imagem e o neutro, Blanchot observa que a imagem não é apenas, como era para Sartre, um ato no qual se vence ou nega o nada, é também o olhar do nada que nos fixa (...). A imagem neutra é sempre um jogo antropomórfico de semelhanças viscerais e inversamente nela os traços do humano dissolvem-se no impessoal.” (SAN PAYO, 2008, p. 19)

${ }^{25}$ Apenas se se deixa escutar; murmura: a existência precede a essência, não podemos dar nada por descontado, está tudo sempre por recomeçar.

26 "Mas, precisamente, a essência da literatura escapa a toda determinação essencial, a toda afirmação que a estabilize ou mesmo que a realize; ela nunca está ali previamente, deve ser sempre reencontrada ou reinventada. Nem é mesmo certo que a palavra 'literatura' ou a palavra 'arte' correspondam a algo de real, de possível ou de importante. (...) Não se deve dizer que todo livro pertence apenas à literatura, mas que cada livro decide absolutamente o que ela é.” (BLANCHOT, 2005, p. 294) 
essência da literatura é ao mesmo tempo a questão sobre a essência do ser e do ente em geral ${ }^{27}$. O que arranca o escritor do seu quarto, sem que deixe a sua cadeira, é essa abertura fundamental da palavra poética e da ficção literária, que não nos abre à essência de si mesma (a literatura é impossível, um puro errar) sem nos abrir ao mesmo tempo à essência do ser (que é não ter essência, apenas existência) ${ }^{28}$. Negação de negação, a palavra poética traz à superfície (afirma) tudo aquilo que a palavra mundana (o dia) deixa de lado para fazer sentido ${ }^{29}$ : que o mundo é precário, que a existência repousa sobre o nada, que o homem é uma invenção de si mesmo (a noite) ${ }^{30}$.

Logo, à pergunta sobre a necessidade e o sentido da literatura, no exato momento em que a história denega a efetividade das suas obras, Blanchot responde elevando a questão ao nível de uma interrogação fundamental, que tem a totalidade da existência como objeto (objeto inominável, elusivo) $)^{31}$. Nessa mesma medida, "a obra não é de modo algum, para o homem que se põe a escrever, um recinto fechado no qual permanece em seu eu tranquilo e protegido, ao abrigo das dificuldades da vida. Talvez ele acredite estar protegido contra o mundo, mas é para expor-se a uma ameaça muito maior, e mais perigosa, porque ela o encontra desprevenido: aquela que the vem do fora, do fato de que ele se mantém no fora. E contra essa ameaça ele não deve defender-se, deve, pelo contrário, entregar-se a ela" (BLANCHOT, 2005, p. 316).

Tudo isso quer dizer que o escritor é aquele que, pelo seu sacrifício, isto é, pelo sacrifício da verdade, da efetividade, da utilidade da sua palavra, nos conduz além do que nos é familiar, arrancandonos aos projetos comuns e às coisas feitas ou por fazer, convidando-nos a um espaço imaginário onde o que está em jogo é o sentido do que somos e do que (ainda) não somos, do que poderíamos ser.

As teses ontológicas de Blanchot autorizam, nesse sentido, uma leitura política: o destino aberto, irresoluto, trágico da literatura, lembra-nos das limitações de qualquer ação histórica e de qualquer projeto político para colmatar as aspirações humanas. Irredutível à lógica dos meios para os fins, da conservação da vida e dos projetos que abrem o presente ao futuro, a literatura é signo de uma

\footnotetext{
${ }^{27}$ Busca obscura, difícil e atormentada. Experiência essencialmente arriscada em que a arte, a obra, a verdade e a essência da linguagem são questionadas e se põem em risco. (BLANCHOT, 2005, p. 288)

28 Reconhecemos nisso tanto ecos do existencialismo sartriano como da ontologia heideggeriana. É interessante notar que Sartre foi sensível a isso, mesmo se na sua resenha de Amibadab, descarta o parentesco com a sua concepção do existencialismo de forma liminar - "Kafka e Blanchot, para fazer-nos ver desde fora a nossa condição sem recorrer aos anjos, descreveram um mundo de cabeça para baixo. (...) Mas, nos perguntamos, por que há que descrever o mundo justamente ao contrário? Que plano mais estúpido descrever o homem de cabeça para baixo! (SARTRE, 1960) -, ressaltando apenas o segundo - "o homem está sozinho, só ele decide o seu destino, ele inventa a lei à qual se submete; cada um de nós, estranho a si mesmo, é para todos os outros uma vítima e um verdugo; inutilmente se tenta transcender a condição humana, seria melhor adquirir um sentido nietzschiano da terra; bem, a sabedoria do senhor Blanchot parece pertencer a essas 'transcendências' das quais falou Jean Wahl a propósito de Heidegger (SARTRE, 1960). É interessante notar que algumas da primeiras recepções das obras de Sartre e Blanchot os situam sobre um mesmo horizonte; ver, por exemplo, Kenneth Douglas, "Blanchot and Sartre", in: Yale French Studies, n. 3, 1949, pp. 85-95.

29 "Blanchot retém da filosofia hegeliana da linguagem nomeadamente as ideias de supressão e de negação. É em 1949, em 'A literatura e o direito à morte', que a sua interpretação hegeliana da literatura é mais evidente; ele teorisa claramente a sua concepção da linguagem como supressão do mundo e acesso ao ser na ideia." (MIRAUX, 1998, p. 14)

30 "Propondo uma equivalência entre aquilo que a nomeação exclui - coisa que ao longo de "A literatura e o direito à morte" chama de 'existência' - e o 'Ser' heideggeriano, Blanchot pode efetuar uma espécie de descontextualização heideggeriana de Hegel. Porque da mesma forma em que o Heidegger de 'O que é a metafisica?' afirmava que toda investigação humana é construída sobre a exclusão da Nada, a palavra (o nome) tem uma fundação abismal similar na existência, isto é, em tudo aquilo que o conceito deixa de lado. (...) Logo, o paradoxo central da literatura seria: como fazer para falar da fundação escura dada pela 'existência' quando todo dizer assenta na sua própria exclusão? A literatura deveria ser uma tentativa de trazer à luz aquilo que a linguagem ordinária deixa de lado, procurando ser a 'revelação do que a revelação destrói'." (SCHWARTZ, 1998) A resposta de Blanchot é uma afirmação problemática: a literatura é esse esforço que se concreta em cada obra de atingir o fora, mas nenhuma obra é esse esforço realizado - a literatura é infinita ou impossível (sempre por vir): uma aproximação assintótica à sua essência (determinada e traída em cada obra). "[Há] uma perspectiva trágica associada a toda a criação artística: a da impossibilidade radical de realizar o seu projeto se não é repetindo-o infinitamente. (...) Não se trata apenas de sugerir simbolicamente a necessidade da uma reescritura ou de uma releitura, mas concretamente de pensar a obra como repetição." (MIRAUX, 1998, p. 18-19)

31 “Em todo o caso, temos em Blanchot a ideia de uma vida como 'ultimidade, queimação inconsumável', não submetida, portanto, à intencionalidade da consciência.” (PÉLBART, 2007, p. 69)
} 
parte do homem que recobrem as suas determinações mundanas. A literatura não possui verdade alguma, mas a sua forma abre-nos a essa verdade sobre nós mesmos: o mundo no qual vivemos não esgota o sentido da nossa existência.

Daí que a literatura se encontre essencialmente ligada a um tempo de aflição e desamparo, mas também a um tempo de chance. De desamparo, porque pela literatura o homem é lançado fora do que pode e fora de todas as formas de possibilidade (impotência da escrita), colocando em causa a suficiência dos seus empreendimentos concretos e, mais profundamente, o fundamento da ação histórica em geral, a partir de uma dissolução de todos os limites que se revela sob a forma da angústia (aflição). De chance, porque pela literatura, ao mesmo tempo exílio da verdade e risco de um jogo inocente, se afirma a pertença do homem a uma exterioridade sem intimidade e sem limite ${ }^{32}$.

Escrever não é uma simples fuga perante os impasses do mundo da praxis, mas uma paixão pelo absoluto para além das suas determinações históricas; uma tentativa de "superar a esterilidade deste mundo fechado" (MIRAUX, 1998, p. 24) ${ }^{33}$, uma possibilidade da qual nem a cultura nem a linguagem nem a história dão conta: uma possibilidade que não pode nada (é o reverso da efetividade), mas que subsiste no homem como signo do seu próprio ascendente.

Na obra o homem fala, mas a obra dá voz, no homem, ao que não fala, ao inominável, ao inumano, ao que é sem verdade, sem justiça, sem direito, onde o homem não se reconhece, não se sente justificado, onde não está mais presente, onde não é homem para ele, nem homem perante Deus, nem deus diante de si mesmo. (BLANCHOT, 2011b, p. 253) ) $^{34}$

Não que a literatura seja uma explicação ou uma compreensão mais alta do homem. Se a literatura diz alguma coisa do homem, é a sua inumanidade, isto é, remete para uma dimensão inexplicável, incompreensível do homem ${ }^{35}$ - e isso sempre sem garantias, sem razão nem fundamento.

Mas, nessa medida, a literatura é uma força cáustica, capaz de destruir, ao mesmo tempo que destrói a sua própria autoridade, os prestígios da reflexão séria, dessa reflexão que impõe o seu sentido ao mundo. $\mathrm{Na}$ sua recusa superabundante (soberana) dos imperativos da ação, e na sua exploração defectiva (não verdadeira) do fundo da existência, remete-nos para um lugar estranho, onde o indefinido do erro pode quiçá preservar-nos do disfarce do inautêntico. Para o homem medido e comedido, o quarto (como o mundo) é um lugar estritamente determinado, mas para o homem desértico que é o escritor o mesmo espaço é infinito - um espaço no qual erra sem destino ${ }^{36}$.

A analogia entre o escritor e o homem do deserto não é inocente. O escritor é um profeta para Blanchot, um profeta sem deus, um profeta do desastre, que fala do desamparo do homem moderno e da sua sina trágica: não há estrelas no horizonte, não há sequer oásis no caminho, e a marcha está

\footnotetext{
32 "Que livros, escritos, linguagem sejam destinados a metamorfoses às quais já se abrem, sem que o saibamos, nossos hábitos, mas se recusem ainda nossas tradições; que as bibliotecas nos impressionem por sua aparência de outro mundo, como se, nelas, com curiosidade, espanto e respeito descobríssemos, pouco a pouco, depois de uma viagem cósmica, os vestígios de outro planeta mais antigo' imobilizado na eternidade do silêncio, só não o perceberíamos se fôssemos muito distraídos." (BLANCHOT, 2005, p. 296) "Numa carta de Rilke, endereçada a Clara Rilke, encontramos esta resposta: 'As obras de arte são sempre os produtos de um perigo corrido, de uma experiência conduzida até ao fim, até ao ponto em que o homem não pode mais continuar'. A obra de arte está ligada a um risco, é a afirmação de uma experiência extrema." (BLANCHOT, 2011b, p. 257)

$33 \mathrm{O}$ escritor recusa, portanto, colocar a sua atividade específica em função das leis do mundo, dando expressão a um universo de inexistência, a um espaço sem lugar, a uma temporalidade desligada do tempo (MIRAUX, 1998, 1998, p. 22).

34 "[A] arte, presença do homem a si mesmo" (BLANCHOT, 2011b, p. 234)

35 A literatura aparece vinculada ao estranho da existência que o ser repudia, a existência que escapa a qualquer tipo de categorização (BLANCHOT, 2011a, p. 348). Ou digamos, melhor, para utilizar uma enigmática fórmula de Bataille, que, aquém da história, a literatura coloca problemas humanos e eternamente pós-revolucionários, isto é, problemas antropológicos, metafísicos, trágicos.

36 "The firmness of the ground beneath our feet is seemingly replaced by the infinite interconnections between words, where one word refers to another word and so on, and where they could not constitute a totality or complex of concepts that would designate a discernible reality. It is true that we might speak of the universe or world of a novel or a poem, but this universe or world is not the world or universe in which we live or exist; rather, it is the work's own world and universe, one that, unlike ours, is infinitely open, allusive and enigmatic spurring us on to endless interpretations that forever remain unsatisfied.” (HAASE \& LARGE, 2001, p. 33)
} 
sempre por recomeçar ${ }^{37}$. Profeta sem entendimento do futuro, ou de um entendimento impotente (Cassandra), o escritor não conduz o homem a nenhuma terra prometida (como afirmara Sartre); permanece no erro e faz do erro uma forma de vida e um modo da crítica (é Abraão, e não Moisés) ${ }^{38}$. Se nos oferece uma morada, é a da sua impermanência; se nos revela uma verdade, é a da sua impostura ${ }^{39}$.

A literatura não é uma resposta ${ }^{40}$. A literatura é simplesmente a forma de manter as questões em aberto, as suas e as do homem: sacrifício da verdade da obra (da sua efetividade histórica) pelo qual é negada a verdade das respostas que dão uma forma ao mundo e um sentido à história.

Blanchot nunca é tão claro sobre o significado dessas palavras enigmáticas como numa nota d'O espaço literário; então escreve:

Para esclarecer essa questão a um nível mais próximo da atualidade histórica, poderia dizerse: quanto mais o mundo se afirma como futuro e dia pleno da verdade onde tudo terá valor, onde tudo conterá sentido, onde o todo se realizará sob o domínio do homem e para seu uso, mais parece que a arte deve descer para esse ponto onde nada ainda tem sentido, mais importa que ela mantenha o movimento, a insegurança e o infortúnio do que escapa a toda a apreensão e a todo o fim. O artista e o poeta receberam a missão de nos recordar obstinadamente o erro, de nos voltarmos para esse espaço em que tudo o que nos propomos, tudo o que adquirimos, tudo o que somos, tudo o que se abre na terra e no céu, retorna ao insignificante, onde aquilo que se aborda é o não sério e o não verdadeiro, como se talvez brotasse aí a fonte de toda a autenticidade. (BLANCHOT, 2011b, p. 270).

O escritor resiste, mas não toma posição - tal é a forma do seu engajamento possível (HAASE \& LARGE, 2001, p. 120) ${ }^{41}$. Ao fim da história, responde com a infinidade do erro, da errância, e, nesse

\footnotetext{
37 “ $[\mathrm{O}]$ desastre, literalmente, é dis-astro, privação do astro, separação da estrela, perda da fonte de luz, distanciamento de qualquer centro de gravidade. O desastre consiste em que já não se gravita em torno de um centro, ou de uma noção central, seja ela ontológica ou teológica, ética ou metafísica, 'ser ou ente, Deus ou sujeito', comenta Bideent. É o reino da pura queda, da exterioridade sem centro, do extravio.” (PÉLBART, 2007, p. 66)
}

38 "D]izer: a experiência da literatura é ela mesma experimento de dispersão, é a aproximação do que escapa à unidade, experiência do que é sem entendimento, sem acordo, sem direito - o erro e o fora, o inacessível e o irregular." (BLANCHOT, 2005, p. 301)

${ }^{39}$ Sartre verá nisso um defeito da escrita de Blanchot (“esse jovem escritor, ainda inseguro de sua maneira”), não o princípio da sua autenticidade. "En Blanchot habría [segundo Sartre] una trascendencia similar a la kafkiana, una trascendenciaausencia, que podría en movimiento el deseo del hombre, pero que lo frustraría, ya que este quedaría cazado en un incesante remitir, entre medios que reenvían hacia otros medios, por lo que no podría estabilizarse nunca esta operación; no habría aquí ningún 'oasis' donde hacer pie. Esta relación con la trascendencia eventualiza lo que Blanchot llama el 'desastre', que es, en su literalidad, un 'des-astro', el quiebre de una referencia a una Estrella (infinito, Dios, etc.), el término de la fijeza del ser." (René Baeza, "Resistencias: Economía de la Inscripción en Jacques Derridá”, p. 169). "Para Kafka (...) existe sem dúvida uma realidade transcendente, mas está fora de alcance e não serve senão para nos fazer sentir mais cruelmente o desamparo do homem no seio do humano. O senhor Blanchot, quem não acredita na transcendência, subscreveria sem dúvida esta opinião de Eddington: 'Descobrimos a estranha pegada na margem do Desconhecido. Para explicar a sua origem edificamos teorias sobre teorias. Por fim, conseguimos reconstruir o ser que deixou essa pegada e acontece que esse ser somos nós mesmos'. De aí o plano de um ‘retorno ao humano’ do fantástico. Não se empregará certamente para provar nem para edificar. (...) Nada de súcubos, nem de fantasmas, nem de fontes que choram: não há senão homens e o criador do fantástico proclama que se identifica com o objeto fantástico. O fantástico já não é, para o homem contemporâneo, senão uma maneira entre cem de desenvolver a sua própria imagem." (SARTRE, 1960)

40 Toda pergunta produz uma resposta aparente (na obra), mas essa resposta é novamente exposta à dúvida, numa busca que não tem fim (e isso é a literatura).

41 "[T] hus a form of responsibility (though no less essential) wholly different from that which has brutally marked the relations of literature and public life since 1945, known to us through the simplistic name of 'Sartrean engagement'. Notably, the result of this is that the revue cannot interest itself directly in political reality, but always in an indirect manner. This search for the 'indirect' is one of the major tasks of the revue" (BLANCHOT apud HAASE \& LARGE, 2001, p. 122) "But what then is the responsibility of an author? We know it already: the interruption of the political on the part of the intellectual. Now we are able to understand the whole sentence that we have quoted in part above: 'To write is to engage oneself; but to write is also to disengage oneself, to commit oneself irresponsibly'. The danger of literature lies, as we have seen, in that it speaks with an anonymous voice, breaking through the identification of meaning with authority. That is to say that writing is dangerous precisely because it is innocent, putting in question the institutionalization of power. Here in 
sentido, a literatura é o mundo ao contrário, a história invertida. Se aparece ao mundo moderno como coisa do passado é apenas porque pertence a um tempo espúrio: o tempo do infortúnio do extravio e da migração fecunda, isto é, o tempo no qual todos os projetos acabam por fracassar, mas também o tempo no qual tudo pode começar de novo. ${ }^{42}$

Inútil para um mundo regido pela lógica hegemônica da ação eficaz, a literatura nega o mundo de uma forma singular (subtraindo-nos à familiaridade das suas configurações históricas), mas dessa negação resulta ao mesmo tempo a afirmação mais pródiga, a afirmação do começo, da possibilidade de um novo ponto de partida (abrindo-nos ao inabitual, ao insólito, ao que não tem relação com o nosso mundo nem com o nosso tempo $)^{43}$.

Alguém se fecha num quarto para escrever e, à margem da história, de costas para o mundo, deixa ouvir um zumbido de inseto (BLANCHOT, 2011a, p. 341) - fala do homem antes do homem, da folha em branco ${ }^{44}$. Só no seu quarto, é reclamado pelo mundo (daí a sua aflição) e ao mesmo tempo possuído pela inspiração (daí a sua impotência). Não pode escolher. Deve responder a ambas as solicitações, a essas ordens absolutas e absolutamente diferentes que exigem tudo dele, ao mesmo tempo, sem conciliação nem compromisso ${ }^{45}$ : "Deve salvar o mundo e ser o abismo, justificar a existência e dar a palavra ao que não existe; deve estar no final dos tempos, na plenitude universal, e ser a origem, o nascimento do que acaba de nascer" (BLANCHOT, 2011a, p. 322).

Nesse sentido, no escritor se conjugam, segundo uma lógica cujo desenvolvimento se confunde com a própria literatura, um princípio de ação e a incapacidade de atuar, a renúncia a tudo o que não tem a escritura por fim, e a impossibilidade de encontrar na escritura um fim em si próprio, porque, exposta ao erro, à errância, a escritura começa e acaba sempre fora de si mesma - no mundo, na história, etc. ${ }^{46}$

Onde radica então o poder da literatura, que tem lugar num mundo que considera o seu trabalho um jogo nulo ou perigoso? Em que consiste o dom do poeta, que abre um caminho para a escuridão da existência sem conseguir nunca apreender a sua verdade obscura? Por que um homem como Kafka pensava que, se tinha que errar o seu destino, ser escritor era a única forma de errá-lo com verdade? Por que alguém se fecha num quarto para escrever?

Hölderlin: apenas é visto fora um dia ou outro, e desvaria. Kafka: prefere mijar nas calças a levantar-se da mesa. Proust: não sairá nunca mais.

the 1960s, as much as before in the 1930s, Blanchot's politics remains revolutionary, and it is not until an essay called 'Intellectuals under Scrutiny' that Blanchot criticizes his own revolutionary conception of politics, especially his stance from the 1930s, making his peace with the democratic foundation of our societies." (HAASE \& LARGE, 2001, p. 121)

42 "Essa presença de ser [própria da obra de arte] é um evento. Esse evento não acontece fora do tempo, caso contrário a obra seria somente espiritual, mas, por ela, acontece no tempo um outro tempo, e no mundo dos seres que existem e das coisas que subsistem acontece, como presença, não um outro mundo, mas o outro de todo o mundo, o que é sempre distinto do mundo." (BLANCHOT, 2011b, p. 248) "[O]rigem que sempre nos precede e é sempre dada antes de nós, pois é a aproximação daquilo que nos permite distanciarmo-nos: coisa do passado, num sentido diferente do de Hegel" (BLANCHOT, 2011b, p. 250)

43 “Mesmo a 'ausência de tempo' para a qual nos conduz a experiência literária não é, de modo algum, a região do intemporal, e, se pela obra de arte somos chamados ao abalo de uma iniciativa verdadeira (a uma nova e instável aparição do fato de ser), esse começo nos fala na intimidade da história, de uma maneira que talvez dê chance a possibilidades históricas iniciais." (BLANCHOT, 2005, p. 290)

44 “A literatura não é uma simples trapaça, é o perigoso poder de ir em direção àquilo que é, pela infinita multiplicidade do imaginário. A diferença entre o real e o irreal, o inestimável privilégio do real, é que há menos realidade na realidade, pois ela é apenas a irrealidade negada, afastada pelo enérgico trabalho da negação, e pela negação que é também o trabalho. É esse menos, essa espécie de emagrecimento, de afinamento do espaço, que nos permite ir de um ponto a outro, à maneira feliz da linha reta. Mas é o mais indefinido, essência do imaginário, que sempre impede K. de alcançar o Castelo, assim como impede, por toda eternidade, que Aquiles alcance a tartaruga' e talvez o homem vivo de se juntar a si mesmo, num ponto que tornaria sua morte perfeitamente humana e, por conseguinte, invisível." (BLANCHOT, 2005, p. 140)

${ }_{45}$ Blanchot reflete aqui a sua leitura de Barthes, a quem dedicará páginas interessantíssimas em O livro por vir. Vale a pena confrontar, por exemplo, as seguintes linhas de O gran zero da escrita: "A história se apresenta perante o escritor como o advento de uma opção necessária entre diversas morais da linguagem - o obriga a significar a literatura segundo possíveis dos quais não é o dono".

46 "Vimos que a literatura se atribui tarefas inconciliáveis. Vimos que do escritor ao leitor e do trabalho à obra ela passa por momentos opostos e só se reconhece na afirmação de todos os momentos que se opõem.” (BLANCHOT, 2011a, p. 349) 
Blanchot: "Bastam-nos alguns passos para sair do nosso quarto, alguns anos para sair da nossa vida. Mas suponhamos que, nesse espaço estreito (...) nós nos perdêssemos.” (BLANCHOT, 2005, p. 137)

Então?

Essa pergunta continua a colocar-se para nós, não como simples denuncia do escritor e da literatura, das suas imposturas e das suas mistificações, mas como afirmação problemática de uma inoperância radical que, isolada em estado puro, é quiçá capaz de colocar em questão a obra humana em geral, na sua sobredeterminação histórica moderna, enquanto projeto total ou totalitário.

E não se trata simplesmente de mais uma figura da consciência infeliz: é também uma chance. Assombra-nos, como um fantasma, nos tira o sono, inclusive quando não parece possível responder a essa pergunta: a pergunta que é a literatura para si, a pergunta que é o homem para si, à margem das tarefas do dia, das promessas e das empreitadas do dia, no alto da noite, a sós, no segredo de um quarto, perante uma folha em branco.

\section{REFERENCIAS}

AUSTER, Paul. La invención de la soledad. Tradução espanhola de M. Eugenia Ciocchini. Barcelona: Edhasa, 1990.

BARTHES, Roland. O grau zero da escrita: seguido de novos ensaios críticos. Tradução portuguesa de Mário Laranjeira. São Paulo: Martins Fontes, 2004.

BLANCHOT, Maurice. A parte do fogo. Tradução portuguesa de Ana Maria Scherer. Rio de Janeiro: Rocco, 2011.

BLANCHOT, Maurice. O espaço literário. Tradução portuguesa de Álvaro Cabral. Rio de Janeiro: Rocco, 2011b.

BLANCHOT, Maurice. O livro por vir. Tradução portuguesa de Leyla Perrone-Moisés. São Paulo: Martins Fontes, 2005.

DOUGLAS, Kenneth. "Blanchot and Sartre”. In: Yale French Studies, n. 3, 1949, pp. 85-95.

DURAS, Marguerite. Escribir. Tradução española de de Ana María Moix. Barcelona: Tusquets Editores, 1994.

HAASE, Ullrich \& LARGE, William. Maurice Blanchot. New York: Routledge, 2001.

MIRAUX, Jean-Philippe. Maurice Blanchot. Quiétude et inquiétude de la littérature. Paris: Editións Nathan, 1998.

PELBART, Peter P. "Excurso sobre o desastre”. In: Queiroz, A., Moraes, F., Velasco e Cruz, N. (org.). Barthes / Blanchot: um encontro possível? Rio de Janeiro, 7Letras, 2007.

QUEIROZ, A., ALVIM, L., OLIVEIRA, N. (org.). Apenas Blanchot! Rio de Janeiro: Pazulin Ed., 2008 . 
SAN PAYO, Patricia. "O 'fora' de Blanchot: escrita, imagem e fascinação”. In: Anghel, G. Pellejero, E. 'Fora' da filosofia: As formas de um conceito em Sartre, Blanchot, Foucault e Deleuze. Lisboa: CFCUL, 2008.

SARTRE, Jean-Paul. "Aminadab o de lo fantástico considerado como un lenguaje”. In: Situaciones I - El hombre y las cosas. Tradução espanhola de Luis Echávarri. Buenos Aires: Losada, 1960.

SCHWARTZ, Stephen Adam. "Faux Pas: Maurice Blanchot on the Ontology of Literature". In: SubStance, v. 27, n. 1, issue 85, University of Wisconsin Press, 1998, pp. 19-47.

Recebido em 11/05/2014.

Aprovado em 13/08/2014. 